\title{
Arboviral and other illnesses in travellers returning from Brazil, June 2013 to May 2016: implications for the 2016 Olympic and Paralympic Games
}

P Gautret ${ }^{1}$, F Mockenhaupt ${ }^{2}$, MP Grobusch ${ }^{3}$, C Rothe ${ }^{4}$, F von Sonnenburg ${ }^{5}$, PJ van Genderen 6 , F Chappuis ${ }^{7}$, H Asgeirsson ${ }^{8}$, E Caumes ${ }^{9}$, E Bottieau ${ }^{10}$, D Malvy ${ }^{11}$, R Lopez-Vélez ${ }^{12}$, M Jensenius ${ }^{13}$, CS Larsen ${ }^{14}$, F Castelli ${ }^{15}{ }^{16}$, C Rapp ${ }^{17}$, V Field ${ }^{18}$, I Molina ${ }_{19}$, E Gkrania-Klotsas ${ }^{20}$, Ś Florescu ${ }^{21}$, D Lalloo 2223 , P Schlagenhauf 24

1. University Hospital Institute for Infectious and Tropical Diseases, Aix-Marseille University, Marseille, France

2. Institute of Tropical Medicine and International Health, Charité - Universitätsmedizin Berlin, Germany

3. Centre for Tropical Medicine and Travel Medicine, Department of Infectious Diseases, Academic Medical Centre, University of Amsterdam, Amsterdam, the Netherlands

4. University Medical Center Hamburg-Eppendorf, Department of Tropical Medicine and Infectious Diseases, Bernhard Nocht Clinic, Hamburg, Germany

5. Department of Infectious Diseases and Tropical Medicine, Ludwig-Maximilian's University of Munich, Munich, Germany

6 . Institute for Tropical Disease, Harbour Hospital, Rotterdam, the Netherlands

7. Division of Tropical and Humanitarian Medicine, Geneva University Hospitals, Geneva, Switzerland

8. Department of Infectious Diseases, Karolinska University Hospital, Stockholm, Sweden

9. Department of Infectious and Tropical Diseases, Hôpital Pitié-Salpétrière, Paris, France

10. Department of Clinical Sciences, Institute of Tropical Medicine, Antwerp, Belgium

11. Department of Internal Medicine and Tropical Disease, University Hospital Centre, Bordeaux, France

12. Tropical Medicine and Clinical Parasitology, Infectious Diseases Department, Ramón y Cajal Hospital, Madrid, Spain

13. Department of Infectious Diseases, Oslo University Hospital, Oslo, Norway

14. Department of Infectious Diseases, Aarhus University Hospital, Denmark

15. University Division of Infectious and Tropical Diseases, University of Brescia, Brescia, Italy

16. Brescia Spedali Civili General Hospital, Brescia, Italy

17. Department of Infectious and Tropical Diseases, Hôpital Bégin, Saint-Mandé, France.

18. InterHealth Worldwide and National Travel Health Network and Centre (NaTHNaC), London, United Kingdom

19. Tropical Medicine Unit Drassanes-Vall d’Hebron, PROSICS Barcelona, Barcelona, Spain

20. Department of Infectious Diseases, Addenbrooke's Hospital, Cambridge, United Kingdom

21. Dr. Victor Babes Clinical Hospital for Infectious and Tropical Diseases, Bucharest, Romania

22. Liverpool School of Tropical Medicine, Liverpool, United Kingdom

23. National Institute for Health Research Unit in Emerging and Zoonotic Infections, Liverpool, United Kingdom

24. University of Zürich Centre for Travel Medicine, WHO Collaborating Centre for Travellers' Health, Epidemiology, Biostatistics and Prevention Institute, Zürich, Switzerland

Correspondence: Philippe Gautret (philippe.gautret@club-internet.fr)

Citation style for this article:

Gautret P, Mockenhaupt F, Grobusch MP, Rothe C, von Sonnenburg F, van Genderen PJ, Chappuis F, Asgeirsson H, Caumes E, Bottieau E, Malvy D, Lopez-Vélez R,

Gautret P, Mockenhaupt F, Grobusch MP, Rothe C, von Sonnenburg F, van Genderen PJ, Chappuis F, Asgeirsson H, Caumes E, Bottieau E, Malvy D, Lopez-Vélez R,
Jensenius M, Larsen CS, Castelli F, Rapp C, Field V, Molina I, Gkrania-Klotsas E, Florescu S, Lalloo D, Schlagenhauf P. Arboviral and other illnesses in travellers returning from Brazil, June 2013 to May 2016: implications for the 2016 Olympic and Paralympic Games. Euro Surveill. 2016;21(27):pii=30278. DOI: http://dx.doi. returning from Brazil, June 2013 to May 2016: imp
org/10.2807/1560-7917.ES.2016.21.27.30278

Article submitted on 24 June 2016 / accepted on 06 July 2016 / published on 07 July 2016

We evaluated EuroTravNet (a GeoSentinel subnetwork) data from June 2013 to May 2016 on 508 ill travellers returning from Brazil, to inform a risk analysis for Europeans visiting the 2016 Olympic and Paralympic Games in Brazil. Few dengue fever cases $(n=3)$ and no cases of chikungunya were documented during the 2013-15 Brazilian winter months, August and September, the period when the Games will be held. The main diagnoses were dermatological (37\%), gastrointestinal (30\%), febrile systemic illness (29\%) and respiratory (11\%).

We analysed travel-associated morbidity in ill travellers returning from Brazil and presenting at 22 EuroTravNet sites during June 2013 to May 2016. As the Olympic and Paralympic Games will take place during August and September, the cooler months in Brazil, we focused on the main vector-bone diseases reported during these months. Very few cases of dengue fever $(n=3)$ and no cases of chikungunya were reported during August and September in three consecutive years. The main syndromic diagnoses were dermatological (37\%; $n=189$ ), gastrointestinal ( $30 \% ; n=152$ ), febrile systemic illness $(29 \% ; n=148)$ and respiratory $(11 \% ; n=58)$.

\section{Findings}

A total of 508 ill returning European travellers were recorded during the study period, June 2013 to May 2016 (Table 1). Most patients were tourists (68\%; $n$ $=339)$ and $27 \%(n=136)$ had documented pre-travel advice. The median duration of travel was 22 days (range: $2-2,588)$. A total of 27 patients were hospitalised ( $5 \%)$.

The main syndromic diagnoses are shown in Table 2. 


\section{FIGURE 1}

Aggregate monthly number of cases of dengue fevera ${ }^{a}$, chikungunya ${ }^{\mathrm{b}}$ and Zika virus infection ${ }^{\mathrm{c}}$ among ill travellers returning from Brazil presenting at EuroTravNet sitesd by month of infectione and aggregate number of returning travellers with any illness, by month of travelf, June 2013-May $2016(\mathrm{n}=273)$

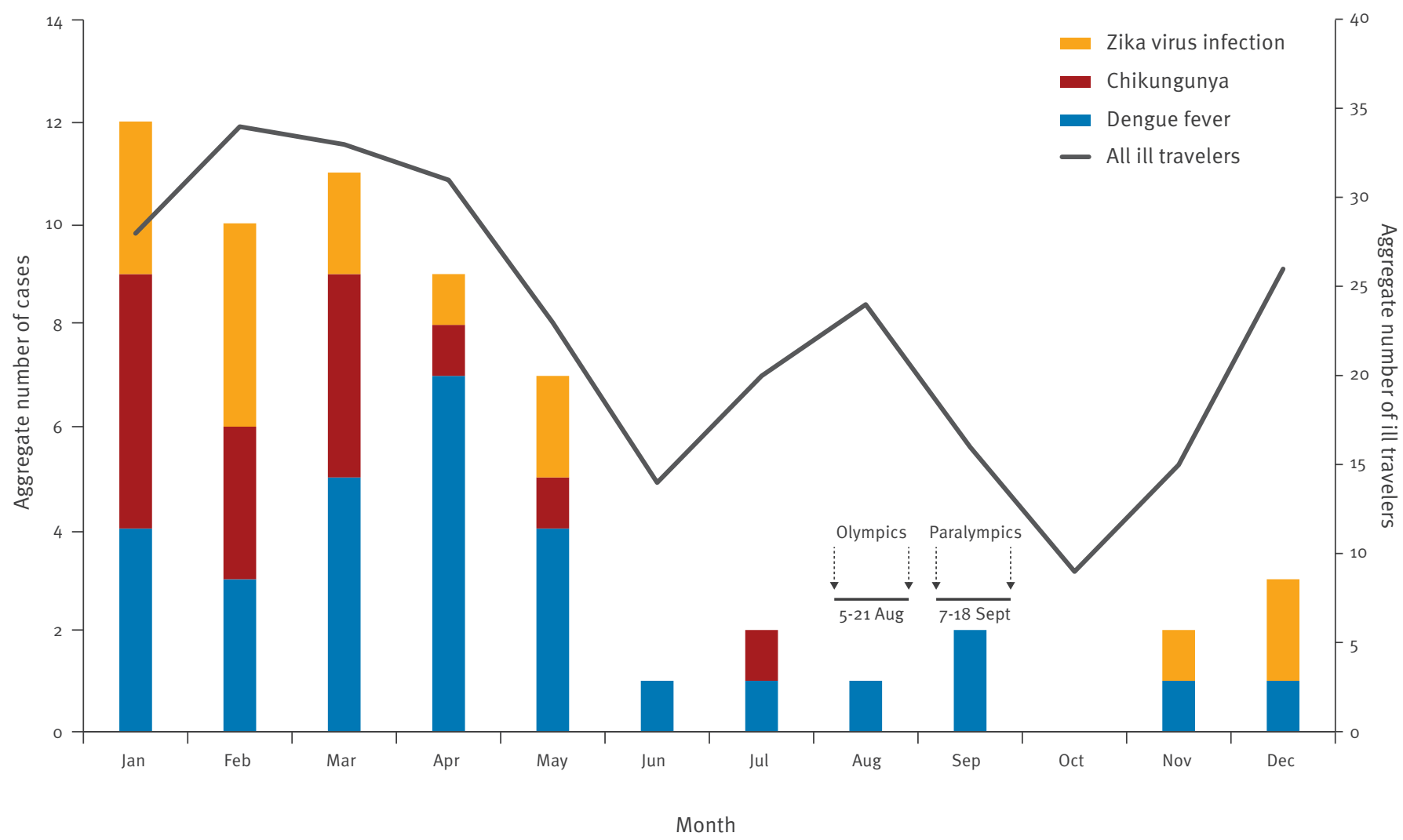

The period of the 2016 Olympic and Paralympic Games is indicated.

a Dengue fever cases were seen at EuroTraveNet sites in each of the study years.

${ }^{\text {b }}$ Chikungunya cases were seen at EuroTraveNet sites in 2014-16 (the end of the study period being May 2016).

' Zika virus has only recently emerged in Brazil [8]. Cases of zika virus infection were seen at EuroTraveNet sites in $2015-16$ (the end of the study period being May 2016). No cases of Zika virus infection in returning travellers from Brazil were reported at EuroTravNet sites from August to September in 2015 .

${ }^{d}$ EuroTravNet, a subnetwork of GeoSentinel [1], comprises European sites specialised in travel or tropical medicine that contribute clinicianbased data on ill travellers [2].

e Based on travel dates, date of symptom onset and known incubation period.

${ }^{\mathrm{f}}$ Travel duration of 22 days or less.

The most frequent specific dermatological diagnoses were parasitic skin infections, in particular cutaneous larva migrans. Arthropod bites and skin and soft tissue infections were also among the most common dermatological conditions.

Most patients with gastrointestinal disease had acute diarrhoea of unknown aetiology, while infection with Giardia intestinalis and geohelminths (i.e. soil-transmitted) accounted for the most frequent aetiological diagnoses.
The most frequent causes of febrile systemic illnesses during the study period were dengue fever, chikungunya and Zika virus infection (ZVI). The number of cases according to month of infection over the study period is shown in the Figure. The first reported case of chikungunya acquired the infection in March 2014, and the first case of ZVI acquired the infection in May 2015. There were three cases of malaria: two Plasmodium falciparum and one $P$. vivax malaria. No deaths were recorded. 
TABLE 1

Demographic and travel characteristics of ill travellers returning from Brazil presenting at EuroTravNet ${ }^{\text {a }}$ sites, June 2013May $2016(\mathrm{n}=508)$

\begin{tabular}{|c|c|}
\hline Characteristic & Number $(\%)^{b}$ \\
\hline Male & $271(53)$ \\
\hline Median age in years (range) & $34(0-79)$ \\
\hline \multicolumn{2}{|l|}{ Pre-travel advice obtained } \\
\hline Yes & $136(27)$ \\
\hline No & $185(36)$ \\
\hline Unknown & $187(37)$ \\
\hline \multicolumn{2}{|l|}{ Travel reason } \\
\hline Tourism & $339(67)$ \\
\hline Visiting friends and relatives & $75(15)$ \\
\hline Business & $72(14)$ \\
\hline Missionary, volunteer, researcher, community service worker, humanitarian, aid worker, education worker, student & $22(4)$ \\
\hline \multicolumn{2}{|l|}{ Travel duration in Brazil, in days } \\
\hline Median (range) & $22(2-2,588)$ \\
\hline$<30$ & $323(64)$ \\
\hline$\geq 30$ & $164(32)$ \\
\hline Not documented & $21(4)$ \\
\hline \multicolumn{2}{|l|}{ Hospitalisation } \\
\hline Yes & $27(5)$ \\
\hline
\end{tabular}

a EuroTravNet, a subnetwork of GeoSentinel [1], comprises European sites specialised in travel or tropical medicine that contribute clinicianbased data on ill travellers [2].

${ }^{\mathrm{b}}$ Unless otherwise specified.

Among those with respiratory syndromes, no causative agent was identified, with the exception of the three influenza cases.

\section{EuroTravNet and study inclusion criteria}

EuroTravNet, a subnetwork of GeoSentinel [1], comprises 22 European sites specialised in travel or tropical medicine that report clinician-based data on ill travellers [2]. Sites enter anonymised data on demographics, travel history, reason for travel, pre-travel advice, hospitalisation, major clinical symptoms and final, clinician-verified diagnoses. In our study, only travellers with Brazil as a single country of exposure were included. Only confirmed and probable diagnoses were included and patients whose only travel was for 'migration' were excluded. Every patient had at least one diagnosis (from a list of 556 possible diagnostic codes). Diagnoses were based on the recognition of a specific causative pathogen using the best reference diagnostic tests available. Syndromic codes were used when clinical indicators suggested a specific diagnosis without identification of a causative pathogen.

\section{Background}

International mass gatherings pose a risk for communicable disease outbreaks and onward rapid, global spread of infection [3]. The Olympic Games will take place mainly in Rio de Janeiro, Brazil, on 5-21 August 2016, followed by the Paralympic Games, on 7-18 September 2016. More than 400,000 visitors to the Games are expected [4]. The European Centre for
Disease Prevention and Control (ECDC) recently issued a health risk assessment for European citizens visiting the Games [5], based mainly on extrapolation of data obtained from the Brazilian population. Data on illness in travellers returning from Brazil will provide additional information on which to base an accurate risk assessment for Europeans attending the Games. A previous study on this topic was conducted by GeoSentinel (the Global Surveillance Network of the International Society of Travel Medicine) among travellers to Brazil between July 1997 and May 2013 [6]. Our study presented here reports more recent data, with a focus on European travellers and mosquito-borne viral infections.

\section{Discussion}

European travellers returning from Brazil during the past three years had a pattern of travel-related illnesses similar to that previously described in a broader population of travellers to Brazil, with the exception of an increase in arboviral infections starting in 2014 [6]. On the basis of our results, mosquito bite prevention, food and water precautions and avoidance of skin contact with soil should be recommended for travellers to Brazil. Vaccination against influenza should be considered for those in risk groups. Vaccination against illnesses such as yellow fever and malaria prevention should be considered, based on individual itineraries in Brazil as detailed in the ECDC health risk assessment [5]. Although no case of measles was reported in our analysis, there is a theoretical risk of contracting 


\section{TABLE 2}

Main syndrome groups and diagnoses of ill travellers returning from Brazil presenting at EuroTravNet sites ${ }^{\text {, }}$ June 2013May 2016 (605 diagnosis in 508 patients)

\begin{tabular}{|c|c|}
\hline Syndrome groups and diagnoses & Number $(\%)^{\mathrm{t}}$ \\
\hline \multicolumn{2}{|l|}{ Dermatological } \\
\hline Total & $189(37)$ \\
\hline Cutaneous larva migrans, hookworm-related & $57(11)$ \\
\hline Insect bite & $38(8)$ \\
\hline Skin and soft tissue infections & $30(6)$ \\
\hline Tungiasis & $8(2)$ \\
\hline Other parasitic infections (myiasis, scabies and cutaneous leishmaniasis) & $7(1)$ \\
\hline Tick bite & $7(1)$ \\
\hline Animal bites requiring rabies post-exposure prophylaxis & $6(1)$ \\
\hline Rash of unknown aetiology, non febrile & $6(1)$ \\
\hline Fungal infection & $5(1)$ \\
\hline \multicolumn{2}{|l|}{ Gastrointestinal } \\
\hline Total & $152(30)$ \\
\hline Acute diarrhoea, aetiology unknown & $43(8)$ \\
\hline Giardiasis & $21(4)$ \\
\hline Intestinal helminthiases (strongyloidiasis, hookworm infection, ascaridiasis) and schistosomiasis & $19(4)$ \\
\hline Other intestinal infections with documented pathogenc & $13(3)$ \\
\hline Chronic diarrhoea (>2 weeks), aetiology unknown & $10(2)$ \\
\hline Irritable bowel syndrome, post infectious & $6(1)$ \\
\hline \multicolumn{2}{|l|}{ Febrile systemic illness } \\
\hline Total & $148(29)$ \\
\hline Unspecified febrile illness & $60(12)$ \\
\hline Dengue fever & $32(6)$ \\
\hline Chikungunya & $15(3)$ \\
\hline Zika virus infection & $14(3)$ \\
\hline Other febrile systemic illness with documented pathogen ${ }^{d}$ & $9(2)$ \\
\hline \multicolumn{2}{|l|}{ Respiratory } \\
\hline Total & $58(11)$ \\
\hline Upper respiratory tract infection & $28(6)$ \\
\hline Influenza-like illness or confirmed influenza & $16(3)$ \\
\hline Pneumonia & $8(2)$ \\
\hline
\end{tabular}

a EuroTravNet, a subnetwork of GeoSentinel [1], comprises European sites specialised in travel or tropical medicine that contribute clinicianbased data on ill travellers [2].

${ }^{b}$ Percentage of patients with a given syndrome or diagnosis; one or more diagnoses are possible for each ill returning traveller.

' Salmonella spp. infection $(\mathrm{n}=5)$, Shigella spp. infection $(\mathrm{n}=4)$, Dientamoeba fragilis infection $(\mathrm{n}=2)$, Campylobacter spp. infection $(\mathrm{n}=1)$, Cryptosporidium spp. infection $(n=1)$.

d Plasmodium falciparum malaria $(n=2)$, P. vivax malaria $(n=1)$, cytomegalovirus infection $(n=1)$, Epstein-Barr virus infection $(n=1)$, visceral leishmaniasis $(n=1)$, leptospirosis $(n=1)$, extrapulmonary tuberculosis $(n=1)$, meningococcal sepsis $(n=1)$.

e Influenza B infection $(n=2)$, influenza A infection $(n=1)$.

measles virus [7] and non-immune travellers should be up to date with their routine vaccinations.

Two limitations of this EuroTravNet analysis are firstly that we captured only ill returning travellers who present at a network site and secondly, we have no denominator data. However, our network has an important sentinel function in identifying new and emerging imported infections and trends [2], as evidenced by our recording the importation of chikungunya cases from Brazil, starting in 2014, in the present study. The first case of ZVI exported from Brazil was reported to
EuroTravNet in May 2015, soon after the first cases were documented locally in Brazil and in a traveller returning to Italy $[8,9]$. Overall, mosquito-borne viral infections acquired by European travellers in Brazil showed a clear seasonal pattern, with most cases of dengue fever and chikungunya being observed between December and May. In the past three years, very few returning travellers with dengue fever and none with chikungunya acquired the infection during August and September, the months the Olympic and Paralympic Games will be held. This seasonal pattern is similar to that observed over recent years in the 
Brazilian population. A recent publication showing a 'heat map' and epidemiological data on local dengue virus transmission in Rio de Janeiro during August to September each year during 2001 to 2015 highlights the fact that these are the 'cold' periods, with minimal transmission of dengue virus [10]. Given that Zika virus is transmitted via the same Aedes aegypti vector, we consider that the risk of acquiring ZVI during the 2016 Olympic and Paralympic Games in Brazil will be low.

Despite this, mosquito prevention measures should be recommended for travellers and pregnant women should be discouraged from travel to Brazil during this period [5]. Furthermore recommendations to prevent onward sexual transmission of Zika virus should be observed; these are constantly updated by the European Commission [11]. Of note, infected travellers may return home to European metropolitan areas with high-density populations of Aedes albopictus [12] and ambient temperatures that are conducive to autochthonous outbreaks of arboviral infections in large susceptible populations. This underscores the importance of surveillance of travel-associated infections and vigilance regarding mosquito control in Europe.

\section{Acknowledgements}

GeoSentinel, the Global Surveillance Network of the International Society of Travel Medicine (ISTM), is supported by a Cooperative Agreement (U50/CCU412347) from the United States Centers for Disease Control and Prevention (CDC) and funding from the ISTM.

Conflict of interest

None declared.

Authors' contributions

P. Gautret and P. Schlagenhauf analysed the results and drafted the manuscript; all authors contributed to revising the manuscript and/or providing data.

\section{References}

1. Harvey K, Esposito DH, Han P, Kozarsky P, Freedman DO, Plier DA, et al. Surveillance for travel-related disease--GeoSentinel Surveillance System, United States, 1997-2011. MMWR Surveill Summ. 2013;62:1-23.PMID: 23863769

2. Schlagenhauf $P$, Weld L, Goorhuis A, Gautret $P$, Weber R, von Sonnenburg F, et al. Travel-associated infection presenting in Europe (2008-12): an analysis of EuroTravNet longitudinal, surveillance data, and evaluation of the effect of the pre-travel consultation. Lancet Infect Dis. 2015;15(1):55-64. DOI: 10.1016/ S1473-3099(14)71000-X PMID: 25477022

3. Abubakar I, Gautret P, Brunette GW, Blumberg L, Johnson $D$, Poumerol G, et al. Global perspectives for prevention of infectious diseases associated with mass gatherings. Lancet Infect Dis. 2012;12(1):66-74. DOI: 10.1016/S14733099(11)70246-8 PMID: 22192131

4. Brasil 2016. 500 days: EMBRATUR expects up to 400 thousand foreign visitors at the Games. 25 Mar 2015. Brazil 2016, [Accessed 30 Jun 2016]. Available from: http://www.brasil2016. gov.br/en/news/500-days-embratur-expects-400-thousandforeign-visitors-games

5. European Centre for Disease Prevention and Control (ECDC). Potential risks to public health related to communicable diseases at the Olympics and Paralympics Games in Rio de
Janeiro, Brazil 2016. 10 May 2016. Stockholm: ECDC; 2016. Available from: http://ecdc.europa.eu/en/publications/ Publications/Risk-assessment-mass\%20gathering-Rio-201610May2016.pdf

6. Wilson ME, Chen LH, Han PV, Keystone JS, Cramer JP, Segurado $A$, et al. Illness in travelers returned from Brazil: the GeoSentinel experience and implications for the 2014 FIFA World Cup and the 2016 Summer Olympics. Clin Infect Dis. 2014;58(10):1347-56. DOI: 10.1093/cid/ciu122 PMID: 24585698

7. Nali LH, Fujita DM, Salvador FS, Fink MC, Andrade HF, Pannuti CS, et al. Potential measles transmission risk in mass gatherings: Are we safe for the Olympic games-Rio 2016? J Travel Med. 2016;23(4):taw026. DOI: 10.1093/jtm/taw026 PMID: 27178161

8. Zanluca C, Melo VC, Mosimann AL, Santos GI, Santos CN, Luz K. First report of autochthonous transmission of Zika virus in Brazil.Mem Inst Oswaldo Cruz. 2015;110(4):569-72. DOI: 10.1590/0074-02760150192 PMID: 26061233

9. Zammarchi L, Tappe D, Fortuna C, Remoli ME, Günther $\mathrm{S}$, Venturi G, et al. Zika virus infection in a traveller returning to Europe from Brazil, March 2015. Euro Surveill. 2015;20(23):21153. DOI: $10.2807 / 1560-7917 . E S 2015 \cdot 20.23 .21153$ PMID: 26084316

10. Castro MC. Zika Virus and the 2016 Olympic Games - Evidencebased Projections derived from Dengue do not Support Cancellation. Travel Med Infect Dis. 2016. Forthcoming. DOI: 10.1016/j.tmaid.2016.06.007

11. European Commission. Outbreak of Zika virus disease. Brussels: European Commission. [Accessed 24 Jun 2016]. Available from: ec.europa.eu/health/zika

12. Valerio L, Roure S, Fernández-Rivas G, Ballesteros AL, Ruiz J, Moreno N, et al. Arboviral infections diagnosed in a European area colonized by Aedes albopictus (2009-2013, Catalonia, Spain). Travel Med Infect Dis. 2015;13(5):415-21. DOI: 10.1016/j. tmaid.2015.06.008 PMID: 26169583 